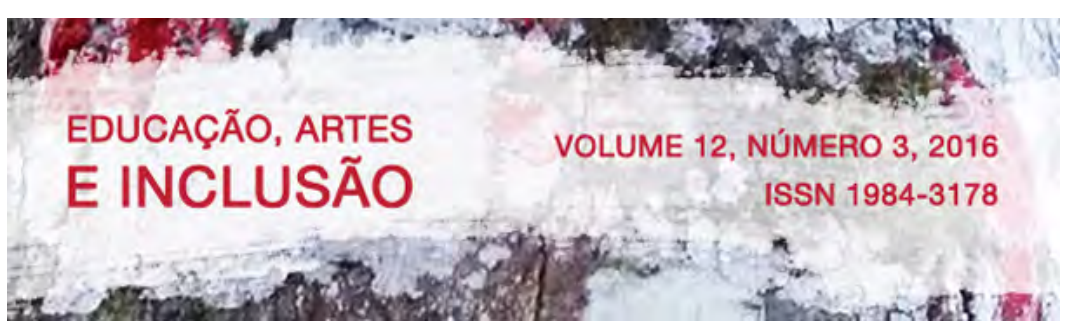

\title{
PANORAMA INCLUSIVO NA PERSPECTIVA DO ENSINO DE CIÊNCIAS EM ESCOLAS DE NÍVEL FUNDAMENTAL DA CIDADE DE CODÓ - MARANHÃO
}

\section{INCLUSIVE PROSPECT IN PERSPECTIVE OF SCIENCE TEACHING IN SCHOOLS FIRST LEVEL OF CODÓ CITY - MARANHÃO}

DOI: http://dx.doi.org/10.5965/1984317812032016226

Clara Virgínia Vieira Carvalho Oliveira Marques, Evene Thais Austríaco Coelho - UFMA

\begin{abstract}
RESUMO
A presente pesquisa teve como objetivo entender o universo do ambiente educacional no tocante ao processo de inclusão social de alunos com deficiências nas escolas de nível fundamental $\left(6^{\circ}\right.$ ao $9^{\circ}$ ano $)$ da cidade de Codó - Maranhão. A partir deste trabalho, obteve-se uma visão panorâmica das condições de acessibilidade das escolas e a quantidade de alunos com deficiências que frequentam as mesmas. Os resultados evidenciaram que o processo de ensino-aprendizagem das ciências para alunos com deficiências no ensino regular segue-se a partir de medidas tradicionais abordadas pelos professores, uma vez que a falta de uma formação e ou capacitação profissional na área da educação especial ou educação inclusiva é considerada por unanimidade dos entrevistados com um dos maiores entraves para o desenvolvimento da inclusão nos ambientes educacionais.
\end{abstract}

PALAVRAS-CHAVES: Percepções dos professores; Inclusão Social; Ensino de Ciências.

\begin{abstract}
This research aimed to understand the universe of educational environment regarding social inclusion process of students with disabilities in elementary level schools (grades 6 to 9) of the city of Codó Maranhão. From this work, we gave an overview of the accessibility conditions of schools and the number of students with disabilities who attend the same. The results showed that the process of teaching and learning science for students with disabilities in regular education follows from traditional measures addressed by teachers, since the lack of training and or professional training in the field of special education or education inclusive is considered unanimously of respondents with one of the biggest obstacles to the development of inclusion in educational environments.
\end{abstract}

KEYWORDS: Teachers' Perceptions; Social Inclusion; Science Teaching. 


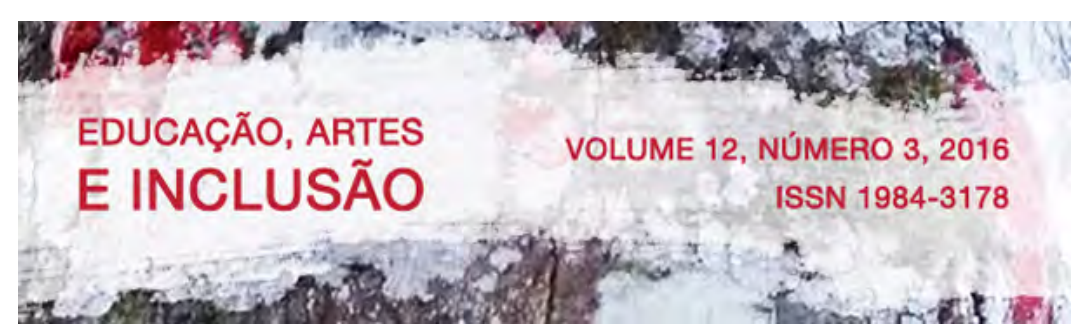

\section{INTRODUÇÃO}

\subsection{ENSINO DE CIÊNCIAS E A DIVERSIDADE}

A área das ciências da natureza vislumbra estudos dos conteúdos intimamente relacionados aos aspectos da vida, matéria e energia, e neste sentido, os Parâmetros Curriculares Nacionais consideram que a aprendizagem de conceitos científicos nesta vertente, desde o Ensino Fundamental, colabora para a formação de cidadãos críticos que se utilizam desses conhecimentos para o saber fazer perante as situações cotidianas (BRASIL, 1997). Para além destes aspectos, Sanmarti (2009) considera que a aprendizagem das ciências da natureza é de extrema relevância não só na formação básica das pessoas em geral, mas principalmente para aqueles que no futuro se dedicarão tanto a ciência quanto a tecnologia.

De acordo com Declara de Direitos Humanos - ONU é importante que o professor seja capaz de compreender a heterogeneidade da sala de aula, valorizando os aspectos do tempo de aprendizagem dos alunos, as suas experiências, sua idade, sua identidade cultural e social, criando condições favoráveis de aprendizagem, incluindo o aluno com qualquer que seja a sua dificuldade na sala de aula.

Ao se tratar do ensino de ciências, Arruda et al. (2006) defendem que além de proporcionar a mediação da aprendizagem de conceitos científicos, o professor tem que diferenciar a sua prática docente para que os alunos possam estabelecer relações entre estes e o mundo em que vive. Nesse sentido, o professor de ciências deve levar em conta a diversidade dos contextos socioculturais em que os alunos estão inseridos e quando se tratar da relação entre ensino de ciências e a diversidade, deve se pensar em um ensino que seja flexível e que sempre se adapte às necessidades dos alunos (MACHADO, 2011).

Para Santos et al. (2008), no tocante à diversidade, a escola é um espaço de intervenção didática, e aspectos relacionados à discriminação e o desrespeito devem ser sanados, visando uma formação ética voltada para a diversidade e a igualdade de oportunidades. Vlado (2015) corrobora com estas ideais, considerando a escola como um espaço de construção de saberes, onde a diversidade é inerente, portanto, o processo formativo dos educandos deve ser voltado para uma formação ética, despertando a importância do respeito e a valorização das diferenças, por meio da prática diária escolar e da reflexão continuada, para que assim se possa encarar a diversidade não mais como um 


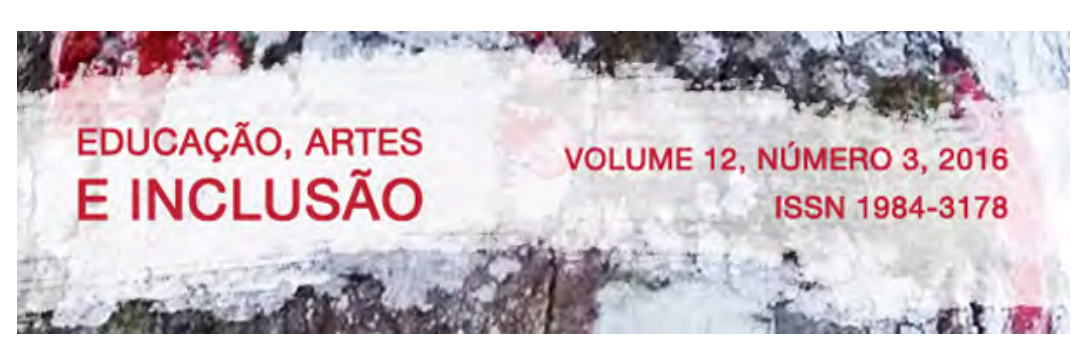

obstáculo.

\subsection{ENSINO DE CIÊNCIAS E O PAPEL DA INCLUSÃO SOCIAL NO ÂMBITO EDUCACIONAL}

Segundo Pellegrinelli (2004), a sociedade de uma maneira geral sempre foi marcada pelas diferenças e pela busca constante de oportunidades para todos. Neste sentido, a ideia de inclusão social é considerada como o ponto chave para uma sociedade mais justa e humana, sendo o caminho de diferenciação em relação ao processo de integração social. No âmbito escolar, Mantoan (2003), afirma que para a efetivação da inclusão social é necessário uma mudança em todo o conjunto escolar para que não só os alunos com deficiências ou com dificuldades de aprendizagem tenham seus direitos garantidos, mas para que todos se conscientizem da importância da garantia desses direitos. Ainda segundo o mesmo autor, a integração social e inclusão social apresentam similaridades quanto à inserção de pessoas deficientes nas escolas, mas diferenciam-se quanto à forma como ambas são inseridas. $\mathrm{Na}$ integração esta inserção ocorre de forma parcial, enquanto que na inclusão esta inserção é de forma incondicional.

Nos últimos anos, principalmente a partir da década de 70 e anos 80, os estudos acerca da inclusão social vêm sendo cada vez mais evidenciados, isto devido à elaboração de leis, decretos e movimentos sociais que incentivam a inclusão das pessoas com deficiências em quaisquer que sejam as esferas sociais (LOVATTO, 2006). No que diz respeito aos direitos e deveres de todos os cidadãos, tanto a constituição nacional (1988), como a Lei de Diretrizes e Base da Educação Nacional (LDB 9.394/96) garantem a educação como item primordial para o alcance da cidadania, devendo ser gratuita no que se refere ao ensino elementar fundamental, como se ilustra a seguir:

\footnotetext{
"A educação, direito de todos e dever do Estado e da família, será promovida e incentivada com a colaboração da sociedade, visando ao pleno desenvolvimento da pessoa, seu preparo para o exercício da cidadania e sua qualificação para o trabalho (BRASIL, 1998)".

"É dever da educação dar atendimento educacional especializado gratuito aos educandos com necessidades especiais, preferencialmente na rede regular de ensino (LDB, 1996)".
} 


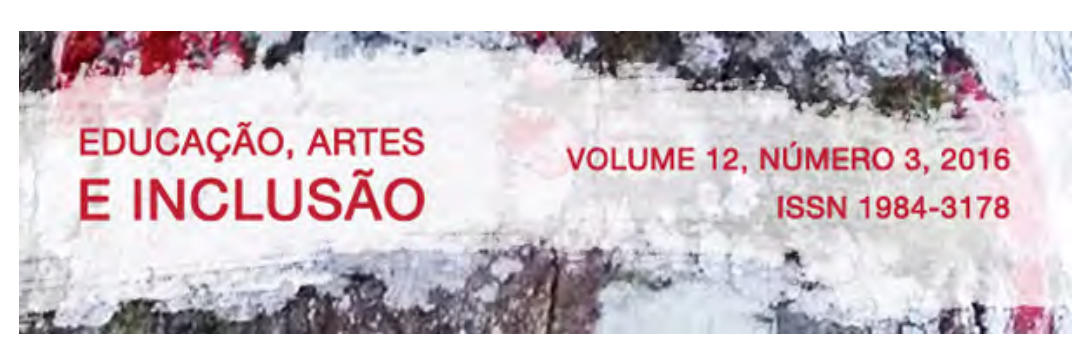

Este atendimento especializado aos alunos com necessidades especiais deve ser realizado preferencialmente na rede regular de ensino, mas também, pode ser encaminhado para as escolas especiais de modo permanente, quando ficar claramente demonstrado que a educação na classe regular seja incapaz de atender as necessidades especiais dos alunos (BRASIL, 1994).

Sob a ótica destes aspectos, Pellegrinelli (2004) afirma que é por esta razão que a inclusão é considerada desafiadora e tem provocado inquietações principalmente na classe dos educadores, uma vez que o papel principal destes é construir um processo de ensino e aprendizagem que abranja toda a diversidade. Vlado (2015) também defende que um dos grandes desafios para os professores é apresentar propostas de um ensino verdadeiramente inclusivo, como espaço acessível, onde a diversidade seja o reflexo da própria sociedade a partir das diferenças que constroem os cidadãos. Para Santos et al. (2008), a inclusão social se preocupa com o todo, e em se tratando de ambiente escolar, tanto os professores quanto o conjunto escolar devem suprir às necessidades de cada aluno que se apresente para matrícula.

No tocante ao ensino e aprendizagem de ciências da natureza, de acordo com Lippe et al. (2009), o grande desafio atualmente é a forma do trabalho mediado pelas propostas inclusivas, uma vez que trabalhar nesta perspectiva requer tanto das escolas quanto dos professores romperem com qualquer forma de exclusão social, pois a educação é um direito garantido pela constituição para todo e qualquer ser humano, além disso, o principio fundamental da escola inclusiva é o de que todas as crianças devem aprender juntas, sempre que possível, independentemente de quaisquer dificuldades ou diferenças que elas possam ter (BRASIL, 1994). Desta forma, o ensino de ciências deve atender as necessidades de todos os indivíduos no sentido de transformá-los em homens e mulheres críticos e participativos, além de proporcionar a construção de um conhecimento cientifico que possa saber fazer a leitura de mundo (CHASSOT, 2002).

Com base na importância que a inclusão social apresenta e considerando os aspectos que vêm sendo discutidos atualmente em todos os seguimentos e esferas sociais, principalmente no baixo índice de trabalhos que envolvam temáticas de ensino de ciências e inclusão social, a presente pesquisa teve por objetivo pontuar as percepções dos professores de ciências quanto ao processo de inclusão social que ocorrem (se ocorrem) nas escolas da rede pública do município de Codó - Maranhão. Neste sentido, entendeu-se como necessário 


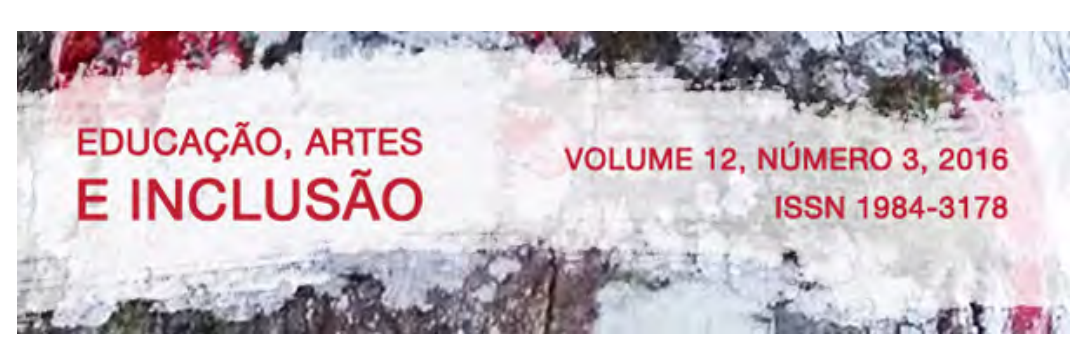

levantar questionamentos que vislumbrem o panorama de inclusão, infraestrutura escolar para a inclusão efetiva de alunos com deficiências e também do perfil de formação de professores para atuarem de forma bem sucedida em questões de pesquisas levantadas, como:

- Quais as percepções dos professores de ciências da cidade de Codó sobre o processo de Inclusão Social?

- Quais as práticas inclusivas utilizadas pelos professores de Ciências Naturais para a realização do trabalho docente?

- Quais as principais dificuldades encontradas pelo professor de ciências para a realização do trabalho docente dentro das propostas inclusivas?

\section{ABORDAGEM METODOLÓGICA}

\subsection{CONTEXTUALIZAÇÃO DA PESQUISA}

O aspecto metodológico desta pesquisa consistiu-se dentro de uma abordagem qualitativa, priorizando o contato direto com o ambiente questionado, buscando enfatizar a perspectiva dos participantes no sentido de valorizar mais o processo do que o produto (LÜDKE e ANDRÉ, 1986).

Assim, tratando-se dos sujeitos dessa pesquisa, realizou-se inicialmente o levantamento de todas as escolas de Ensino Fundamental (EF) da zona urbana da cidade de Codó - Maranhão, do $6^{\circ}$ ao $9^{\circ}$ ano, da Rede Pública de Ensino (RPE). Em seguida, foram feitas visitas in lócus, contactando com gestores e professores de ciências para apresentação da pretensão de trabalho, bem como convite de participação no mesmo, subsidiada com uma breve explicação sobre o trabalho desenvolvido e as referências teóricas das pesquisadoras.

\subsection{PROCEDIMENTOS DE COLETA E ANÁLISE DOS DADOS}

Para a coleta dos dados foram utilizados os seguintes instrumentos:

- Questionários semiestruturados com perguntas fechadas e abertas; 


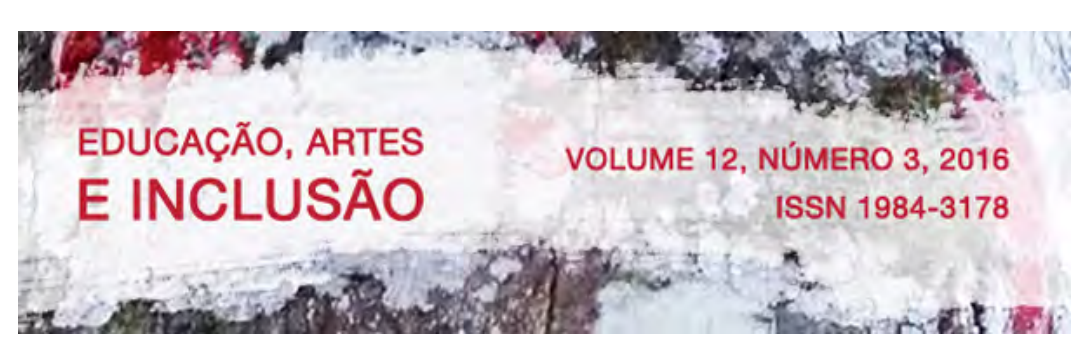

suplementação curricular a fim de contribuir para o progresso dos alunos com deficiências no ensino regular (CARLETO et al., 2013).

Ao se tratar de profissionais capacitados para atuarem com alunos portadores de deficiências, apenas uma escola conta com profissional para atendimento especializado. No que diz respeito às condições de acessibilidade, a Associação Brasileira de Normas Técnicas $\mathrm{ABNT}$ orienta que um ambiente acessível é aquele que deve ir além dos aspectos infraestruturas (ABNT, 2004). Nas escolas em questão, pode-se verificar que de acordo com os itens avaliados, somente 01 escola segue o padrão de acessibilidade, visto que apresenta tanto os aspectos físicos quanto apoio pedagógico para subsidiar o acesso e a permanência de alunos com deficiências, conforme demonstrado na Tabela 01.

Tabela 01: Quadro Demonstrativos das Condições de Acesso em Relação à Infraestrutura e Recursos Humanos.

\begin{tabular}{|c|c|c|}
\hline \multicolumn{3}{|c|}{ Condições de Acessibilidade das Escolas de Ensino Regular $\left(6^{\circ}\right.$ ao $9^{\circ}$ ano $)$} \\
\hline \multirow{2}{*}{$\begin{array}{c}\text { Aspectos Avaliados: Infraestrutura e } \\
\text { Recursos Humanos }\end{array}$} & Presença & Ausência \\
\hline & Número de Escolas & Número de Escolas \\
\hline Rampas & 13 & 0 \\
\hline Portas largas & 13 & 0 \\
\hline Escola plana & 13 & 0 \\
\hline Banheiros adaptados & 10 & 3 \\
\hline Salas Multifuncionais & 02 & 11 \\
\hline Profissionais capacitados & 01 & 12 \\
\hline
\end{tabular}

Gallo (2011) fez uma análise da acessibilidade das pessoas com deficiência física nas escolas de Chapecó-SC e os resultados foram semelhantes aos obtidos nesta pesquisa, onde, das 27 escolas observadas, nenhuma se encontrou em acordo com os itens que levou em consideração em sua pesquisa. Nesse sentido, é importante salientar que não só o a cidade de Codó - Maranhão vem enfrentando problemas relacionados às questões de acessibilidade para efetiva inclusão social nas escolas, mas sim, é uma problemática de âmbito global. Segundo 


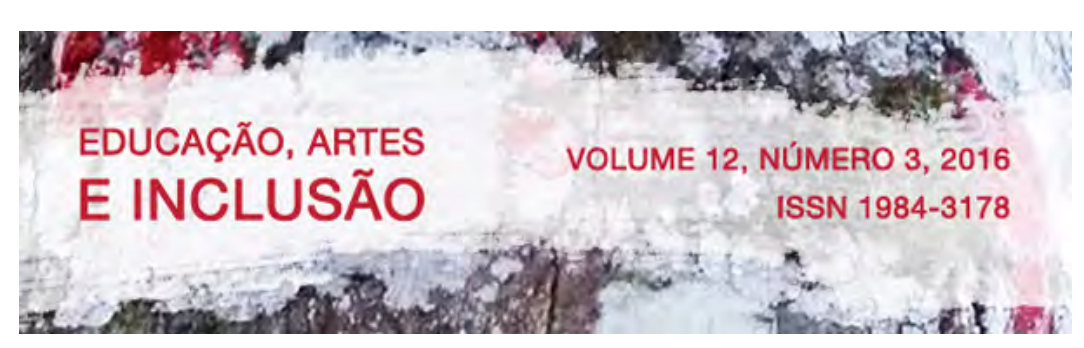

Segundo os gestores, o que justifica a inconsistência entre os dados do INEP e os obtidos nas escolas, é o fato, em especial, das condições oferecidas pelas mesmas, ocasionando a desistência e a evasão desses alunos. Além disso, outro aspecto relacionado foi à necessidade de busca de tratamentos médicos que acarretam constantes mudanças de residências para outras cidades. Outro ponto inquietante observando na pesquisa foi a constatação da omissão de informações por parte dos familiares, uma vez que no ato da matrícula, algumas famílias não deixam explicita a deficiência de seus filhos, logo a escola não tem como especificar e/ou caracterizar seu conjunto de alunos para direcionamento de atividades inclusivas, sendo apenas no ato do exercício da docência constatada a necessidade de tratamento especial à alguns alunos.

Nesta ótica, considera-se importante que a família esteja envolvida no processo de inclusão social, uma vez que colaborando com o fornecimento de informações das necessidades especificas de seus filhos para os professores poderiam facilitar o planejamento de atividades bem sucedidas e alcançar efetivamente o objetivo de aprendizagem (MANTOAN, 2003). Deste modo, os professores devem estar em sintonia para que de fato estes ajustes de orientação familiar sejam sanados o mais breve possível, uma vez que este dinamismo deveria ocorrer já no início do ano letivo, por conscientização dos pais da importância de explicitarem as deficiências dos filhos no ato da matricula, promovendo ações sociais na própria escola.

Além da importância do apoio familiar no processo de inclusão, observou-se que as adaptações do currículo escolar também são importantes no sentido da oferta de escolas inclusivas, uma vez que não cabe em um paradigma tradicional de educação, onde os alunos devem ser vistos como sujeitos construtores do currículo, e não apenas objeto do mesmo, cabendo à escola refletir sobre o papel da educação (FOGLI et al., 2008).

\subsection{CARACTERIZAÇÃO DOS SUJEITOS}

Nesta sessão buscou-se vislumbrar o perfil dos professores de ciências que realizam o trabalho docente com alunos das escolas pesquisadas em relação à sua formação base, formação específica e estudos na área da Educação Especial e ou Educação Inclusiva. Como somente 04 escolas apresentam alunos com deficiências, tratou-se de trabalhar somente com 


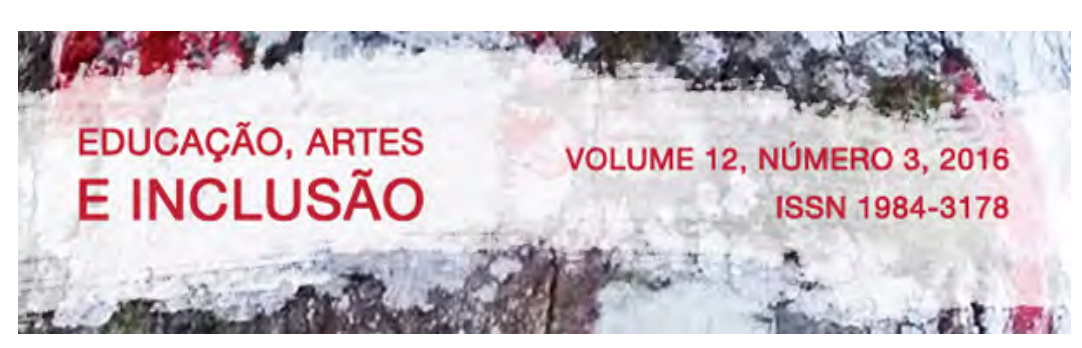

os 05 professores de ciências que acompanham esses alunos. As informações foram organizadas na Tabela 03.

Assim, verificou-se que 02 professores de ciências têm formação superior em biologia e matemática, 01 professor formado em letras e 01 professor formado em física, 01 dos professores tem graduação em química e 01 professor em matemática. Quando se refere à formação em Educação Especial ou Educação Inclusiva, foi constatado que nenhum dos 05 professores apresenta alguma formação nesta área. Isso comprova que os professores de ciências mesmo tendo que contemplar as atividades para alunos deficientes não apresentam uma formação apropriada para o saber fazer com essas adversidades, uma vez que uma formação na área Educação Especial ou Educação Inclusiva constitui-se em um dos principais aspectos para o avanço das escolas inclusivas (BRASIL, 1994).

Com relação a cursos/estudos em nível de formação continuada na área da Educação Especial, teve-se declarado que 02 professores não apresentam cursos nessa área, 01 professor participou de seminários sobre inclusão promovidos por entidades públicas de ensino, 01 professor tem curso de extensão na área da inclusão. Nesta mesma linha, 02 dos entrevistados declararam ter trabalhos aleatórios executados em ocasiões excepcionais, como por exemplo, trabalhos em associação dos cegos do próprio município.

Tabela 03: Perfil dos professores de Ciências quanto à Formação condizente ao trabalho com alunos especiais.

\begin{tabular}{|c|c|c|c|c|}
\hline \multicolumn{5}{|c|}{ Perfil dos Professores de Ciências em relação à Formação em Educação Especial } \\
\hline Código & $\begin{array}{l}\text { Formação } \\
\text { Superior }\end{array}$ & $\begin{array}{c}\text { Formação em } \\
\text { Educação Especial }\end{array}$ & $\begin{array}{l}\text { Cursos na área da } \\
\text { Educação Especial }\end{array}$ & $\begin{array}{l}\text { Trabalhos na área da } \\
\text { Educação Especial }\end{array}$ \\
\hline $\mathbf{P}_{1}$ & $\begin{array}{l}\text { Biologia e } \\
\text { Matemática }\end{array}$ & Não & Não & $\begin{array}{c}\text { Trabalho na Associação } \\
\text { dos Cegos }\end{array}$ \\
\hline $\mathbf{P}_{2}$ & Letras & Não & $\begin{array}{l}\text { Disciplina na } \\
\text { Graduação }\end{array}$ & Não \\
\hline $\mathbf{P}_{3}$ & Física & Não & Não & Não \\
\hline $\mathbf{P}_{4}$ & $\begin{array}{l}\text { Biologia e } \\
\text { Matemática }\end{array}$ & Não & $\begin{array}{l}\text { Participação em } \\
\text { Seminário sobre } \\
\text { Inclusão }\end{array}$ & Apresentação/Música \\
\hline $\mathbf{P}_{5}$ & $\begin{array}{l}\text { Química e } \\
\text { Matemática }\end{array}$ & Não & $\begin{array}{c}\text { Curso via } \\
\text { Internet/Estado }\end{array}$ & Não \\
\hline
\end{tabular}




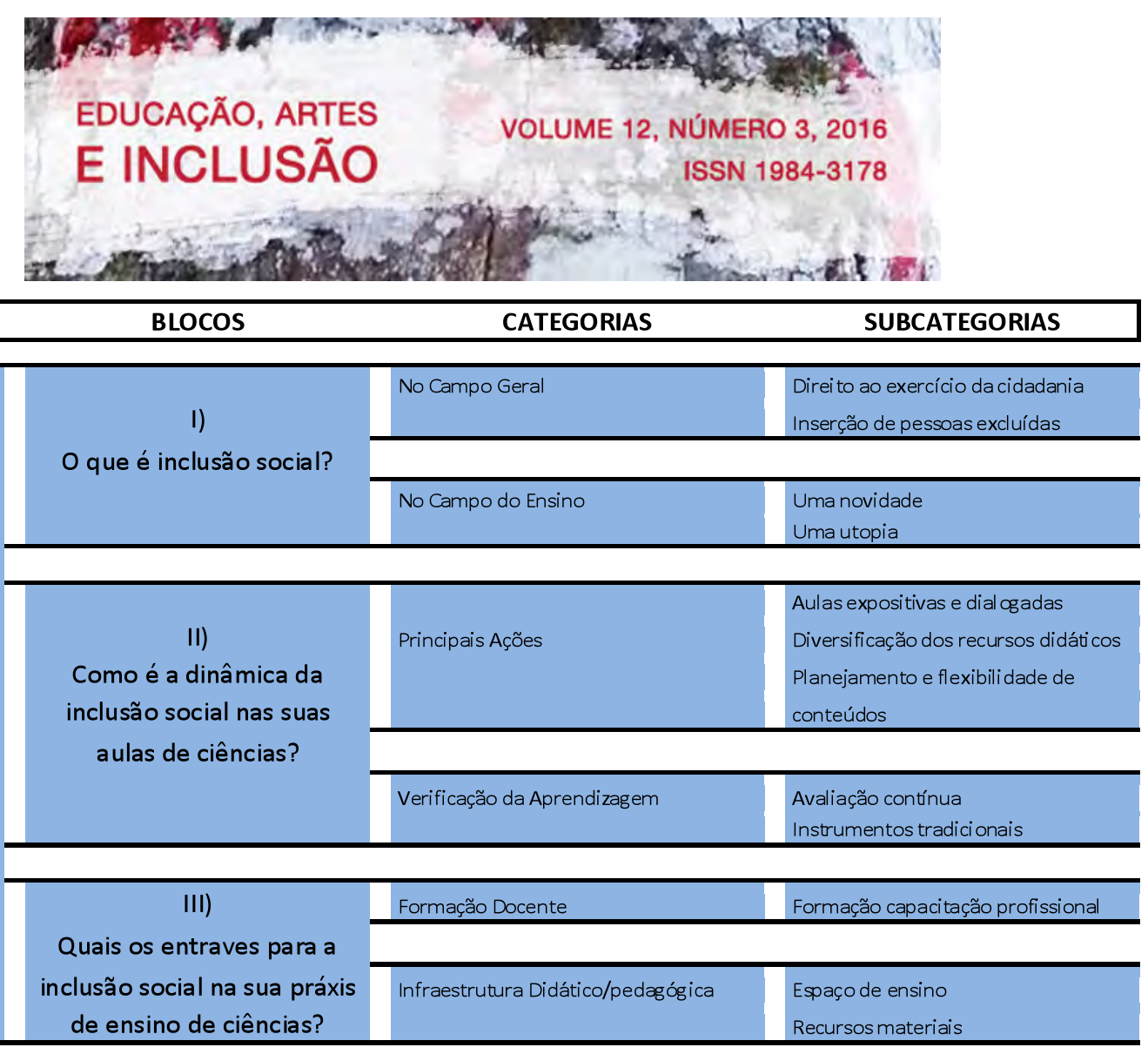

Figura 02: Rede Sistêmica das Percepções dos Professores de Ciências da Natureza sobre a Inclusão Social.

\subsubsection{BLOCO I: O QUE É INCLUSÃO SOCIAL?}

Este bloco discute as percepções dos professores de ciências quanto ao entendimento sobre inclusão social. Foram suscitadas duas categorias que discutem o objeto de estudo, a saber: (i) No campo geral e (ii) No campo de ensino.

\subsubsection{NO CAMPO GERAL}

Para esta categoria, foram definidas duas subcategorias nas quais as unidades de significados retiradas dos discursos dos professores, suscitaram informações resultando em: (i) Direito ao exercício da cidadania e (ii) Inserção de pessoas excluídas. Estas são demonstradas na Tabela 04 . 


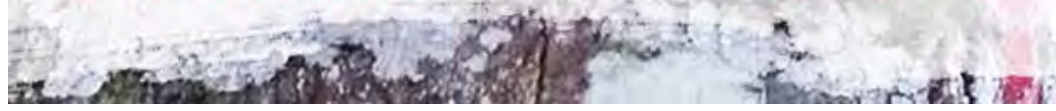

Tabela 04: Descrição das Unidades de Significados para a Categoria: No Campo Geral.

\begin{tabular}{|c|c|c|c|}
\hline \multicolumn{4}{|c|}{1 - O QUE É INCLUSÃO SOCIAL? } \\
\hline $\begin{array}{c}\text { Categoria } \\
\text { No Campo Geral }\end{array}$ & \multicolumn{3}{|c|}{$\begin{array}{l}\text { Esta categoria buscou evidenciar as percepções dos professores de ciências sobre } \\
\text { inclusão social numa visão geral. }\end{array}$} \\
\hline Subcategorias & $\begin{array}{l}\text { Unidades de } \\
\text { Significados }\end{array}$ & Quantidade & Citação \\
\hline $\begin{array}{l}\text { Direito ao exercício } \\
\text { da cidadania }\end{array}$ & $\begin{array}{l}>\text { Igualdade } \\
>\text { Oportunidade } \\
>\text { Direito }\end{array}$ & $60 \%$ & $\begin{array}{l}\text { "[...] todas as pessoas tem o mesmo } \\
\text { direito, independentemente do seu grau de } \\
\text { deficiência }[\ldots] "\left(\mathrm{P}_{1}\right) \text {. }\end{array}$ \\
\hline $\begin{array}{l}\text { Inserção de pessoas } \\
\text { excluídas }\end{array}$ & $\begin{array}{l}>\text { Incluir } \\
>\text { Diversidade }\end{array}$ & $40 \%$ & $\begin{array}{l}\text { "[...] a inclusão é muito importante em } \\
\text { alguns exercícios da Lei, principalmente } \\
\text { no meio social da educação }[\ldots] "\left(\mathrm{P}_{4}\right) .\end{array}$ \\
\hline
\end{tabular}

Dos professores entrevistados, $60 \%$ destes comentaram sobre questões de direito, onde consideraram que a inclusão social está intimamente relacionada com a garantia de oportunidades iguais para todos, como ilustrado na citação do professor $\left(\mathrm{P}_{1}\right)$ presente na Tabela 04. Corroborando com as ideias apresentadas dos professores, Santos et al. (2008) considera que as propostas inclusivas são de certa forma "inquietantes e revolucionárias", uma vez que elas defendem uma inserção incondicional, baseada no argumento de defesa dos direitos e deveres enquanto cidadãos. Ressalta-se também que a Declaração Universal dos Direitos Humanos também considera que todos os cidadãos têm direito a liberdade, a vida, ao acesso em todos os seguimentos e espaços sociais, principalmente à educação (DECLARAÇÃO UNIVERSAL DOS DIREITOS HUMANOS, 1948).

Ao se tratar da subcategoria inserção de pessoas excluídas, pode-se verificar que $40 \%$ dos professores, afirmaram que a inclusão social deve ir além do âmbito educacional, ou seja, em todos os setores da vida das pessoas para atender de fato, os direitos à cidadania, conforme se ilustra com a fala do professor $\left(\mathrm{P}_{3}\right)$ : “[...] entendo a expressão inclusão social como a inserção de pessoas excluídas do bem-estar social [...]”. A Constituição Federal Nacional enquanto instrumento legal enfatiza que todos, independentemente da dificuldade ou deficiência que possuírem, devem estar inserido no meio social não havendo discriminação quanto às limitações (BRASIL, 1988). 


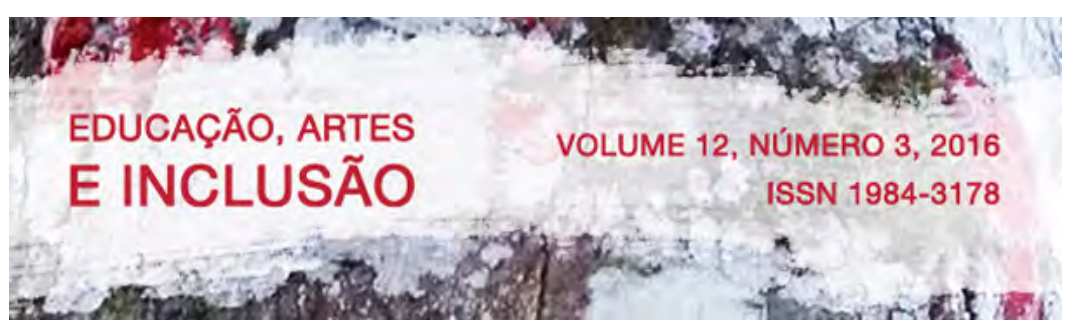

\subsubsection{PRINCIPAIS AÇÕES}

Nesta primeira categoria, buscou-se vislumbrar as ações ou medidas que são aplicadas pelos professores de ciências para a implementação da inclusão social nas suas aulas. Assim, foram organizadas três subcategorias: (i) Aulas expositivas e dialogadas, (ii) Diversificação de Recursos Pedagógicos e (iii) Planejamento e flexibilidade de Conteúdos, conforme mostra a Tabela 06.

Tabela 06: Descrição das unidades de significados para a categoria: Principais Ações.

\begin{tabular}{|c|c|c|c|}
\hline \multicolumn{4}{|c|}{3 - COMO É A DINÂMICA DA INCLUSÃO SOCIAL NAS SUAS AULAS DE CIÊNCIAS? } \\
\hline Categoria & \multicolumn{3}{|c|}{$\begin{array}{l}\text { Para esta categoria buscou-se elucidar as principais ações do processo de ensino } \\
\text { aprendizagem das ciências para alunos com deficiências. }\end{array}$} \\
\hline Subcategorias & $\begin{array}{ll}\text { Unidades de } \\
\text { Significados }\end{array}$ & Quantidade & Citação \\
\hline $\begin{array}{l}\text { Aulas expositivas e } \\
\text { dialogadas }\end{array}$ & $\begin{array}{l}>\text { Exercícios } \\
>\text { Debates }\end{array}$ & $40 \%$ & $\begin{array}{l}\text { "[...] faço perguntas, utilizo a questão do } \\
\text { diálogo nas minhas aulas de Ciências. [...]" } \\
\left(\mathrm{P}_{3}\right) \text {. }\end{array}$ \\
\hline $\begin{array}{l}\text { Diversificação dos } \\
\text { recursos } \\
\text { pedagógicos }\end{array}$ & $\begin{array}{l}>\text { Lúdico } \\
>\text { Experimentos }\end{array}$ & $40 \%$ & $\begin{array}{l}\text { "[...] a prática, o uso de experimentos } \\
\text { proporciona que o aluno vivencie o que está } \\
\text { no livro. Então, procuro principalmente nas } \\
\text { turmas de } 6^{\circ} \text { ano trabalhar mais o lúdico, o } \\
\text { pegar, o fazer }[\ldots . .]^{\prime}\left(\mathrm{P}_{2}\right) \text {. }\end{array}$ \\
\hline $\begin{array}{l}\text { Planejamento e } \\
\text { flexibilidade } \\
\text { conteúdos }\end{array}$ & $>$ Reflexivo & $20 \%$ & $\begin{array}{l}\text { "[...] temos que trabalhar com todos os alunos } \\
\text { de maneira igualitária. Temos que planejar as } \\
\text { nossas aulas de ciências diferenciadas para } \\
\text { facilitar o aprendizado dessas crianças que tem } \\
\text { deficiência }[\ldots] "\left(\mathrm{P}_{1}\right) \text {. }\end{array}$ \\
\hline
\end{tabular}

No tocante a dinâmica das aulas de ciências, observou-se que 02 dos professores afirmaram que durante o processo pedagógico de ensino de ciências, estes buscam incentivar a comunicação por aulas expositivas, levantando questões problemas, para que os alunos possam interagir em sala de aula, acreditando que assim, podem facilitar a sua aprendizagem. Ao tratar-se do ensino de ciências naturais, os Parâmetros Curriculares Nacionais consideram que as aulas expositivas e dialogadas devem propiciar mecanismos para que os alunos possam investigar, compreender e debater, uma vez que no contexto de aprendizagem essas 


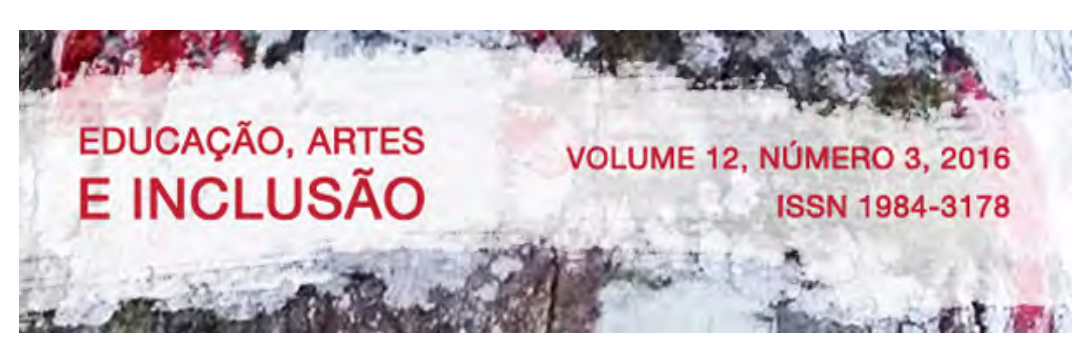

informações devem chegar na mesma proporção a todos os alunos (BRASIL, 1997). Segundo Arruda et al. (2006), o uso de experimentos, o lúdico na qual possibilita o pegar, o fazer, o construir, proporciona uma aprendizagem significativa, além de possibilitar a inclusão em sala de aula.

Encontram-se na subcategoria "diversificação dos recursos pedagógicos”, 02 dos professores, onde suscitaram que as aulas práticas são consideradas de grande relevância para aprendizagem de ciências para alunos com deficiências. Corroborando com as ideias destes professores, Arruda et al.(2006) afirmam que adotar aulas práticas, permite a estes estudantes a construção e elaboração dos conceitos científicos de forma adequada, além de tornar mais clara a maneira como o conhecimento é gerado e produzido.

Ao se tratar da presença de alunos com deficiências, de acordo com Silva et al. (2014), para que a escola regular atenda a diversidade de alunos é necessário dispor de equipamentos e recursos materiais diferenciados, pois são instrumentos fundamentais para que os alunos com deficiências possam encontrar respostas pedagógicas apropriadas e individualizadas, uma vez que práticas pedagógicas bem escolhidas correspondem a qualidade na educação e privilegiam a diversidade. Neste sentido, o professor $\left(\mathrm{P}_{5}\right)$ deixa explicita suas dificuldades ao afirmar que:

\footnotetext{
“[...] Tento mesclar porque também não posso atrasar todo o conteúdo por causa de um aluno e também não posso acelerar deixando-o para trás. Então, uma vez no mês ou duas vezes no mês procuro passar alguma atividade prática de ciências [...] trago filmes que são coisas que eles têm mais facilidade para compreender o conteúdo".
}

Cabe ressaltar que os professores também argumentaram que não é sempre que encontram nas escolas, materiais disponíveis para a realização de atividades diferenciadas, cabendo aos professores construírem recursos se quiserem realizá-las. Assim, constatou-se que os professores tentam diversificar o seu trabalho docente para atender à diversidade, propondo aulas expositivas, uso de práticas experimentais, uso de recursos audiovisuais e também por meio de recursos alternativos. Entretanto, tem-se a necessidade de outros materiais que estejam disponíveis na escola, para que de fato a inclusão seja trabalhada. 


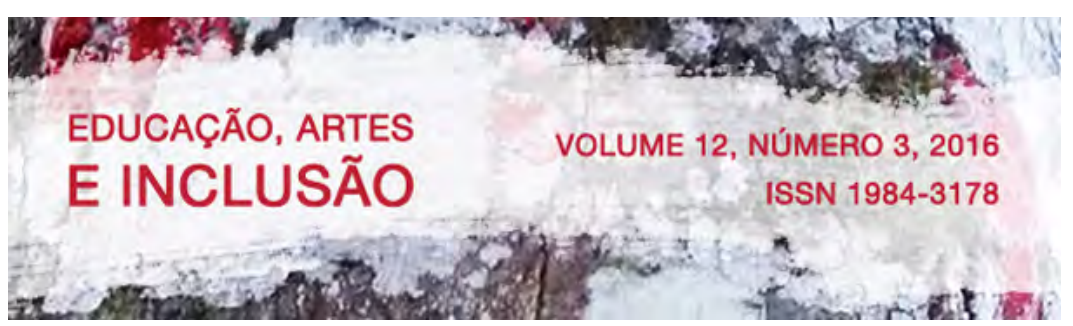

Tabela 07: Descrição das unidades de significados para a categoria: Verificação da Aprendizagem.

\begin{tabular}{|c|c|c|c|}
\hline \multicolumn{4}{|c|}{4 - COMO É A DINÂMICA DA INCLUSÃO SOCIAL NAS SUAS AULAS DE CIÊNCIAS? } \\
\hline $\begin{array}{l}\text { Categoria } \\
\text { Verificação da } \\
\text { aprendizagem }\end{array}$ & \multicolumn{3}{|c|}{$\begin{array}{l}\text { Esta categoria buscou evidenciar os instrumentos de avaliação utilizados pelos } \\
\text { professores ciências no trabalho docente para alunos com deficiências no ensino } \\
\text { regular. }\end{array}$} \\
\hline Subcategorias & $\begin{array}{l}\text { Unidades de } \\
\text { Significados }\end{array}$ & Quantidade & Citação \\
\hline $\begin{array}{c}\text { Avaliação } \\
\text { contínua }\end{array}$ & $>$ Qualitativa & $40 \%$ & $\begin{array}{l}\text { "[...] avalio pelos progressos }[\ldots] \text { na minha } \\
\text { sala tinha um aluno especial que se encontrava } \\
\text { com muita dificuldade de pesquisa, às vezes } \\
\text { colocava as respostas igual como estava no } \\
\text { livro [...] não encaixando com as perguntas, } \\
\text { mas agora vejo que ele evoluiu, ele tem mais } \\
\text { facilidade }[\ldots] "\left(\mathrm{P}_{2}\right) \text {. }\end{array}$ \\
\hline $\begin{array}{l}\text { Instrumentos } \\
\text { Tradicionais }\end{array}$ & $\begin{array}{l}>\text { Participação } \\
>\text { Rendimento }\end{array}$ & $60 \%$ & $\begin{array}{l}\text { "[...] procuro realizar trabalhos em grupos } \\
\text { com todo mundo junto para que se sintam } \\
\text { mais a vontade e também trabalhos } \\
\text { individuais para diagnosticar o rendimento } \\
\text { individualmente }[\ldots]\left(\mathrm{P}_{1}\right) \text { ". }\end{array}$ \\
\hline
\end{tabular}

Neste contexto, 02 dos professores suscitaram que uma avaliação baseada pelos progressos dos alunos é muito importante, uma vez possibilita compreender a dificuldade do aluno e trabalhar em cima dessas limitações, tal como menciona o professor $\left(\mathrm{P}_{4}\right)$ em sua fala:

"[...] Vou trabalhando a deficiência de cada um dentro da sua necessidade na disciplina e tento incluir socialmente na sala de aula. É a única forma que encontrei para trabalhar com eles já que não tem treinamento capacitável para isso".

No que diz respeito ao ato de avaliar, Luckesi (2006) afirma que a avaliação não é resumida somente em provas realizadas ao final de uma unidade, mas sim, é uma ação diária, onde o professor verifica seus objetivos. Reis et al. (2012), também argumentam que quando tem-se a presença de alunos com deficiências em sala de aula, o professor tem que ter o conhecimento das limitações dos alunos, uma vez que no contexto da educação inclusiva, o professor precisa ser ainda mais reflexivo e preparado para uma nova realidade, que é lidar com as diferenças e singularidades de cada um. 


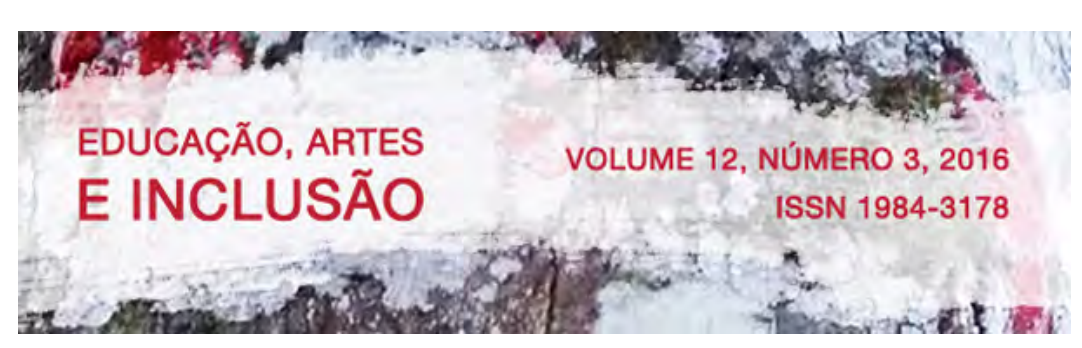

$\mathrm{Na}$ subcategoria "Instrumentos Tradicionais", pode-se verificar que os professores fazem o uso de métodos convencionais para a verificação da aprendizagem em ciências da natureza com os alunos portadores de deficiências, onde 03 destes destacaram a implementação de trabalhos em grupos e/ou trabalhos individuais, bem como o artificio de provas orais, tal como menciona o professor $\left(\mathrm{P}_{3}\right)$ :

“[...] A primeira vez que fiz a prova escrita observei logo as dificuldades, então descartei a possibilidade, no entanto comecei a observar que eles se expressavam melhor fazendo oralmente, tanto provas quanto trabalhos".

Esta linha de avaliação, de acordo com uma boa parte dos professores estimula o aluno a participar das discussões em grupo que acontecem em sala de aula, assim como, as atividades individuais são relevantes para mensurar o rendimento e o nível de aprendizagem dos mesmos.

\subsubsection{BLOCO III: QUAIS OS ENTRAVES PARA A INCLUSÃO SOCIAL NA SUA PRÁXIS DE ENSINO DE CIÊNCIAS?}

O objetivo deste bloco foi evidenciar as principais dificuldades dos professores quanto à implementação do processo de inclusão social no exercício da docência enquanto professores de ciências nas escolas públicas que ofertam ensino regular da cidade. Logo, foram criadas duas categorias que se referem a: (i) Formação Docente e (ii) Infraestrutura Didático / Pedagógico.

\subsubsection{FORMAÇÃO DOCENTE}

Esta categoria salientou as unidades de significados que direcionam para a formação específica do professor para o acompanhamento adequado dos alunos com deficiências nas classes de ensino regular. Desta forma, os dados suscitaram para uma única subcategoria que foi: Formação e/ou capacitação profisssional, conforme mostra a Tabela 08. 


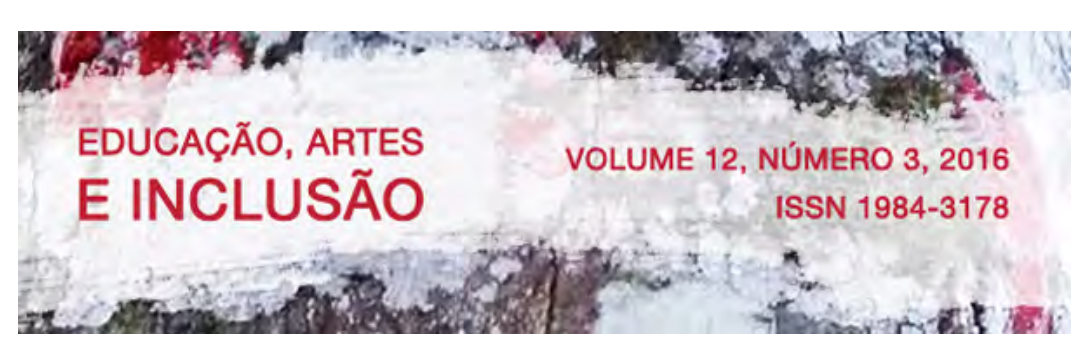

Tabela 09: Descrição das unidades de significados para a categoria: Infraestrutura: Didático/Pedagógico.

\begin{tabular}{|c|c|c|c|}
\hline \multicolumn{4}{|c|}{$\begin{array}{l}6 \text { - QUAIS OS ENTRAVES PARA A INCLUSÃO SOCIAL NA SUA PRÁXIS DE ENSINO DE } \\
\text { CIÊNCIAS? }\end{array}$} \\
\hline $\begin{array}{l}\text { Categoria } \\
\text { Infraestrutura: } \\
\end{array}$ & \multicolumn{3}{|c|}{$\begin{array}{l}\text { Para esta categoria buscou-se identificar as dificuldades dos professores de ciências } \\
\text { quanto à infraestrutura das escolas e os aspectos didático-pedagógicos. }\end{array}$} \\
\hline Subcategorias & $\begin{array}{ll}\text { Unidades de } \\
\text { Significados }\end{array}$ & Quantidade & Citação \\
\hline Espaços de Ensino & $\begin{array}{l}>\text { Acessível } \\
>\text { Estrutura }\end{array}$ & $40 \%$ & $\begin{array}{l}\text { "[...] sempre bato nessa tecla, a "estrutura". } \\
\text { Salas de aula que comporte um número menor } \\
\text { de alunos }[\ldots] \text { salas lotadas não tem aprendizado } \\
\text { tem quantidade mais a qualidade fica zero }[\ldots] \text { " } \\
\left(\mathrm{P}_{4}\right) \text {. }\end{array}$ \\
\hline Recursos Materiais & $\begin{array}{l}>\text { Experimentos } \\
>\text { Lúdico } \\
>\text { Indispensáveis }\end{array}$ & $60 \%$ & $\begin{array}{l}\text { "[...] a falta de recursos materiais dificulta a } \\
\text { realização de uma aula diferenciada, pois você } \\
\text { precisa de material, de logística, de apoio e o } \\
\text { sistema ti oprime por isso" }\left(\mathrm{P}_{2}\right) \text {. }\end{array}$ \\
\hline
\end{tabular}

Além dos aspectos relacionados à falta de uma formação específica na área da educação especial ou educação inclusiva, pode-se observar que outra dificuldade apresentada pelos professores está relacionada à quantidade de alunos por sala de aula, ou seja, os espaços de ensino, citado por 02 dos professores da pesquisa. Para a Resolução CNE/CEB, n.02/2011 - Institui Diretrizes Nacionais para a Educação Especial na Educação Básica, os sistemas de ensino devem matricular todos os alunos, devendo às escolas se organizarem para o atendimento de alunos com deficiências, assegurando as condições necessárias para uma educação de qualidade para todos (BRASIL, 2001). Entretanto, mesmo por exigência da lei, verificou-se in locus que as barreiras para a inclusão social vão desde as condições de acomodações e receptividade desses alunos nas escolas regulares, até a formação profissional dos professores. Portanto, é um problema que precisa ser discutido e levado em consideração, uma vez que se pretende alcançar a plena inclusão social nos sistemas públicos de ensino.

A subcategoria "Recursos Materiais" foi representada pela maior parte dos professores, ou seja, 04 destes comentam sobre os problemas relacionados a falta de recursos materiais nas escolas que também influenciam profundamente no processo de inclusão, 


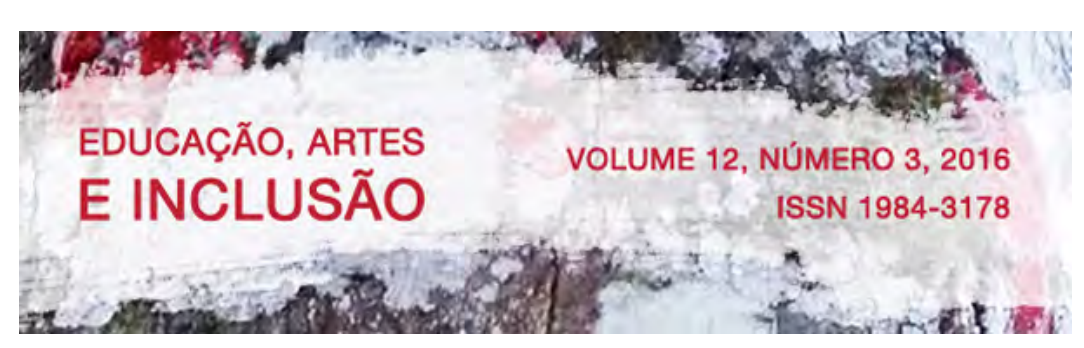

causando bastante desmotivação nos professores, uma vez que como argumentado pelo professor $\left(\mathrm{P}_{2}\right)$ a falta de logística e apoio da escola impossibilitam a realização de atividades diferenciadas, o que conduz aos professores proverem-se de materiais alternativos quando necessário.

\section{CONSIDERAÇÕES FINAIS}

A partir desta pesquisa foi possível verificar a realidade atual das práticas educacionais inclusivas das escolas da cidade de Codó-Maranhão, começando pelos aspectos de acessibilidade, onde ficou evidente que as escolas pesquisadas ainda não apresentam as adaptações necessárias para a efetiva inclusão social dos alunos com deficiências. Pela caracterização dos espaços de ensino de uma maneira geral, percebeu-se que os problemas relacionados à inclusão referem-se principalmente a falta de recursos materiais e de profissionais que atendam efetivamente um número significativo destes alunos.

Evidenciou-se que o apoio familiar é presente neste processo inclusivo, ressaltando que este tem um importante papel na vida da pessoa que é deficiente, sendo de fundamental importância que todos ligados à educação, estejam envolvidos com a inclusão, e assim, educadores e a família, busquem promover parcerias que visem estratégias na solução destas questões de acessibilidade, rompendo com as barreiras atitudinais, burocráticas e de informação.

Os dados revelaram que a falta de uma formação de professores de ciências na área da educação especial e ou educação inclusiva, é um dos maiores entraves para o processo da inclusão social. Portanto, é relevante salientar a importância de discussões, reflexões e de posicionamentos comprometidos com o acesso de todos no ambiente escolar, mas para que essa demanda seja realmente atendida é necessária uma formação permanente que precisa ser assegurada aos profissionais da educação, com a inserção nos cursos de licenciaturas e expansão da oferta de cursos de formação/especialização pelas instituições formadoras.

Esta formação deve ser contínua e permanente, preparando os professores para que possam desenvolver práticas pedagógicas de ciências naturais eficazes e apropriadas para lidar com as adversidades, assegurando a evolução dos alunos no ensino regular. É necessário 


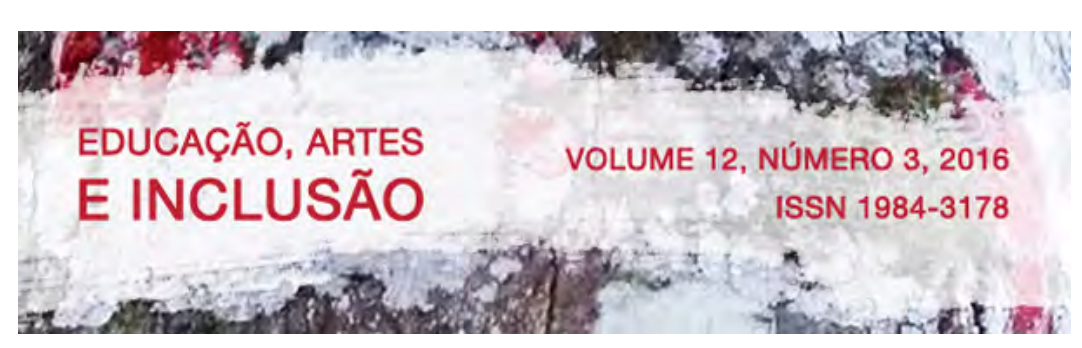

que a escola em parceira com as entidades de governo assegurem recursos que auxiliem o professor de ciências na sua prática escolar diária e ao se tratar de casos infrequentes de alunos com deficiências graves, que os professores possam contar com profissionais especialistas na própria escola, otimizando o ambiente das salas multifuncionais.

Constatou-se que as adaptações do currículo escolar também são necessárias para criar condições de permanência desses alunos nas escolas, uma vez que promover a inclusão requer, sobretudo, uma quebra de paradigmas e reformulação do sistema de ensino para que assim seja possível atender e garantir a permanência de toda a demanda.

\section{REFERÊNCIAS}

ARRUDA, Ana Maria; BANQUINHO, Fátima Tereza; BUENO, Shirley Neves. Ciências no Ensino Fundamental. p. 117-210, 2006. Disponível em:http://www.curriculouerj.pro.br/imagens/docPub/05_ciencia_174.pdf>. Acesso em: 11 de Mar. 2015.

Associação Brasileira de Normas Técnicas. NBR 9050 de 31 de maio de 2004. $2^{\text {a }}$ Edição; Disponível em http://www.mj.gov.br/sedh/ct/corde/dpdh/corde/ABNT/NBR905031052004.pdf $>$. Acesso em: 15 de fev. de 2015.

BRASIL. MINISTÉRIO DA EDUCAÇÃO. Lei Federal no ${ }^{\circ}$ 9.394, de 20 de dezembro de 1996, LDB - Lei de Diretrizes e Bases da Educação Nacional, Diário Oficial da União, 34 p.

Conselho Nacional de Educação. Câmara de Educação Básica. Resolução $\overline{\mathrm{CBE} / \mathrm{CEB}} \mathrm{n}^{\circ}$ 2, de 11 de Setembro de 2001. Institui Diretrizes Nacionais para a Educação Especial na Educação Básica. Brasília: CNE/CEB, 2001.

Constituição (1988). Constituição da República Federativa do Brasil. Brasília, DF: Senado Federal, 1988.

. Declaração de Salamanca e Linha de Ação sobre Necessidades Educativas Especiais. Coordenadoria Nacional para Integração da Pessoa Portadora de Deficiência, 1994.

Secretaria de Educação Fundamental. Parâmetros curriculares nacionais: introdução aos parâmetros curriculares nacionais/Secretaria de Educação Fundamental. Brasília: MEC/SEF, $1997 . \quad$ Disponível em: http://portal.mec.gov.br/seb/arquivos/pdf/livro01.pdf> Acesso em: 07 de Jul. 2015.

BELEI, Renata Aparecida; PASCHOAL, Sandra Regina. Et. al. O uso de entrevista, Observação e Videogravação em Pesquisa Qualitativa. Cadernos de Educação. Pelotas. P. 187 - 199, janeiro/junho 2008. 


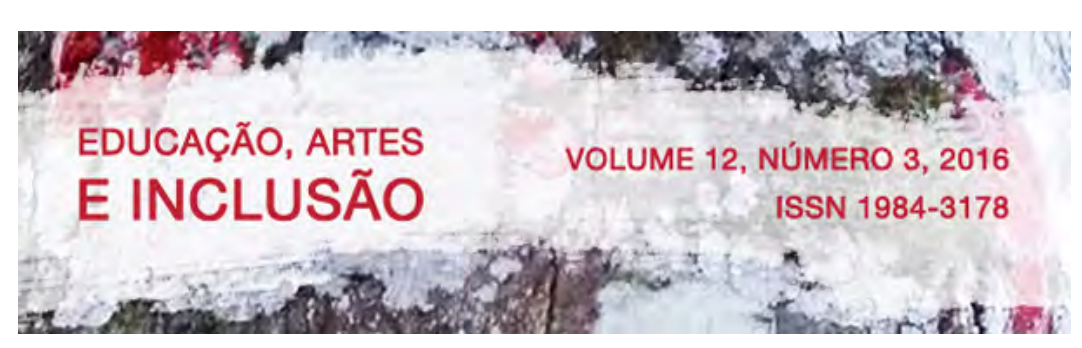

CARLETO, Eliane Aparecida; SOUSA Ivete Cristina. et. al. Sala de Recursos Multifuncionais. Inclusão ou Exclusão Escolar? Revista História e Diversidade, v.2, nº 1 , p.129 - 154. 2013.

CHASSOT, A. Alfabetização científica: questões e desafios para a educação. 2 ed. Ijuí:Unijuí, 2002. 440p.

DECLARAÇÃO UNIVERSAL DOS DIREITOS HUMANOS. Adotada e proclamada pela resolução 217 A (III) da Assembleia Geral das Nações Unidas em 10 de dezembro de 1948. Disponível na Biblioteca Virtual de Direitos Humanos da Universidade de São Paulo: www.direitoshumanos.usp.br > Acesso em: 07 de fev. 2015

FOGLI, Bianca Fátima; FILHO, Lucindo Ferreira, OLIVEIRA, Margareth Maria. Inclusão na educação: uma reflexão crítica da prática. In: SANTOS, Mônica Pereira; PAULINO, Marcos Moreira. Inclusão em Educação: Cultura, Políticas e Práticas. São Paulo, 2008. P. 107 121.

GALLO, Emanuela Gerutti; ORSO, Kelen Daiane; FIÓRO, Franciane Barbieri. Análise da Acessibilidade das pessoas com deficiência física nas escolas de Chapecó-SC e o papel do fisioterapeuta no ambiente escolar. O Mundo da Saúde, São Paulo. P. 201-207.2011.

GOMES, Paulo; BASSO, Sabrina. O Ensino de Biologia mediado por Libras: Perspectivas de Licenciandos em Ciências Biológicas. Trilhas Pedagógicas, Botucatu, v. 4, n. 4, p. 40 - 63, Ago. 2014.

INEP. Instituto Nacional de Estudos e Pesquisas Educacionais Anísio Teixeira. Censo Escolar. Disponível em: <http://portal.inep.gov.br/basica-censo-escolar-matricula $>$. Acesso em: 15 de Jul. 2015.

IBGE. Instituto Brasileiro de Geografia e Estatística. Disponível em: $<$ http://www.ibge.gov.br/home/estatistica/populacao/censo2010/tabelas_pdf/total_populacao_ maranhao.pdf>. Acesso em: 15 de Jul. 2015.

LIPPE, Eliza Mácia Oliveira; CAMARGO, Eder Pires de. O Ensino de Ciências e seus Desafios para a Inclusão: o papel do professor especialista. In: NARDI, R. (Org). Ensino de Ciências e Matemática, I: temas sobre a formação de professores. São Paulo: UNESP, 2009.p. $134-143$.

LOVATTO, Ricardo Blattes. Direito à educação: subsídios para a gestão dos sistemas educacionais: orientações gerais e marcos legais. 2. ed. 343p. Brasília: MEC, SEESP, 2006.

LUCKESI, C. C. (2006). Avaliações da aprendizagem escolar: estudos e proposições. São Paulo: Cortez.

LÜDKE, M.; ANDRÉ, M. E. D. A. (1986) Pesquisa em educação: abordagens Qualitativas. São Paulo: EPU. 


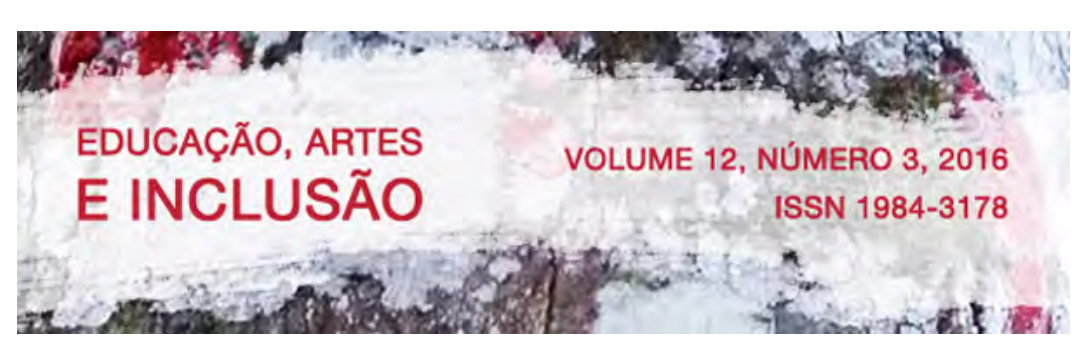

MANZINI, Eduardo José. Entrevista Semi-estruturada: análise de objetivos e de roteiros. In: SEMINÁRIO INTERNACIONAL SOBRE PESQUISA E ESTUDOS QUALITATIVOS. 2, 2004, Bauru. A Pesquisa Qualitativa em Debate. Anais... Bauru: USC, 2004. CD-ROOM. P. 10 .

MARQUES, Clara Virginia. Perfil dos Cursos de Formação de Professores dos Programas de Licenciatura em Química das Instituições Públicas de Ensino Superior da Região Nordeste do Brasil. São Carlos: SP, 2010. 291p. Tese (Doutorado) - Programa de Pós-Graduação em Química, Universidade Federal de São Carlos, Centro de Ciências Exatas e de Tecnologia Departamento de Química, São Carlos, 2010.

MACHADO, Andressa de Oliveira. PCN's para Educação de Alunos com necessidades Especiais. Revista iTEC, v.2, n. 2, p. 39-44, Jul.2011.

MANTOAN, Maria. Inclusão escolar: o que é? Por quê? Como fazer?. São Paulo: Moderna, 2003.

OLIVEIRA, E.; ENS, R. T.; ANDRADE, D. B. S. F.; MUSSIS, C. R. Análise de conteúdo e pesquisa na área da educação. Revista Diálogo Educacional, Curitiba, v. 4, n. 9, p. 11-27, 2003.

PELLEGRINELLI, Maria. Exercício do Respeito. Belo Horizonte: Mazza Edições, 2004.

REIS, Isilene dos Santos; SILVA, Lucicléia Pereira. O ensino de ciências naturais para alunos surdos: concepções e dificuldades dos professores da escola Aloysio Chaves. Revista do EDICC, Concórdia/PA, v. 1, p. 1 - 10, Out/2012.

RODRIGUES, David. Questões preliminares sobre o desenvolvimento de políticas de Educação Inclusiva. Inclusão: R. Edc. Esp, Brasília, v. 4, nº 1, p. 33-40, Jan/Jun. 2008.

SILVA, Franciane da Silva. Análise panorâmica das práticas avaliativas utilizadas pelos professores de ciências da natureza do Ensino Fundamental no Município de Codó-MA. Codó: MA, 2015. 39p. TCC - Curso de Licenciatura em Ciências Naturais, Universidade Federal do Maranhão.

SANTOS, Mônica Pereira; PAULINO, Marcos Moreira. Inclusão em Educação: Cultura, Políticas e Práticas. São Paulo, 2008.

SASSAKE, Romeu Kazumi. Inclusão: Construindo uma sociedade para todos. Rio de Janeiro: WVA, $5^{\circ}$ Edição, 2003.

SANMARTÍ, N. Avaliar para Aprender. Porto Alegre: Artemed, 2009.

SILVA, Tatiane; FRIEDERICHS, Myrna. et. al. A utilização de recursos didáticos no processo de ensino e aprendizagem de ciências de alunos com deficiência visual. Revista Electrónica de Enseñanza de las Ciencias, São Cristóvão, v.13, n. 1, p. 32-47, 2014. 


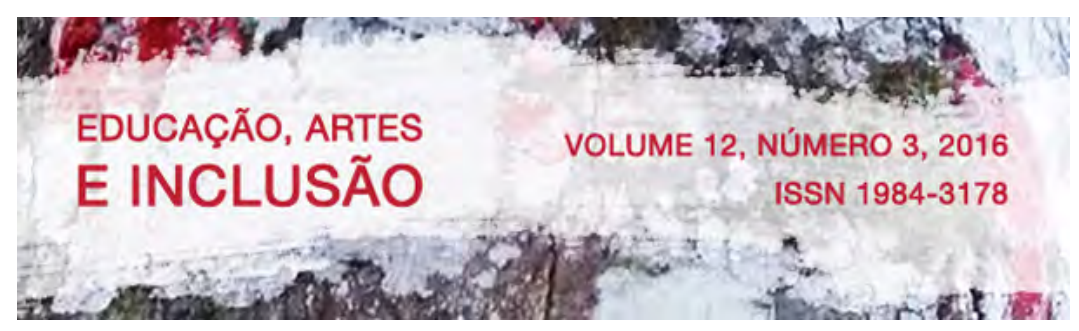

STRAUSS, A.; CORBIN, J. Pesquisa qualitativa: técnicas e procedimentos para o desenvolvimento de teoria fundamentada. 2 ed. Porto Alegre: Artmed, 2008. 288 p.

VLADO, Educação. Orientações Gerais: Educação em Direitos Humanos. São Paulo: Instituto Vladimir Herzog, $1^{\circ}$ Edição, 2015.

WILSON, S. The use of ethnographic techniques in educational research. Review of Educacional Research, 47: 245-265, 1977. 